\title{
Preventive Guidelines for Disinfection and Microbiological Processes during Handling of COVID-19 Samples
}

Muhammad Roman', Sidra saleem¹, Shah Jahan1, Faiz UI Haq1, 2, Husnul Hayat ${ }^{3}$, Abdul waheed', Nadeem Masood ${ }^{4}$

\section{Author Info:}

'Department of Microbiology, University of Health Sciences, Lahore, Pakistan

${ }^{2}$ Center for Biotechnology and Microbiology,

University of Swat, Pakistan 3Pediatric Department, Avicenna Medical College \& Hospital Lahore ${ }^{4}$ Faculty of life sciences university of Central Punjab Lahore

\section{Corresponding Author:}

Muhammad Roman mroman@uhs.edu.pk Tel: +923339463286

\section{ABSTRACT}

Since the first detection and emergence of SARS-CoV-2 in Wuhan, China in December 2019, it has become a worldwide health concern. Human to human airborne transmission and persistence of SARS-CoV-2 on inanimate surfaces or contaminated hands have been documented. Droplets transmission has been recognized as a major source of virus spread. Most of the samples received in the pathology laboratories were for the diagnosis of the corona virus disease-2019 (COVID-19). The highest concentration of SARSCoV-2 has been observed in the respiratory specimens compared to the non-respiratory specimens as the virus is present in lower concentration in urine, blood, and stool. The guidelines in this article present the procedures for disinfection and microbiological processes that should minimize the risk of infection to the laboratory personnel. Surface disinfection with sodium hypochlorite $(0.1 \%)$, ethanol $(62 \%-71 \%)$, or hydrogen peroxide $(0.5 \%)$ with an exposure time of $1 \mathrm{~min}$ is likely to be efficient against SARS-CoV-2. However, the ultraviolet light at $254 \mathrm{~nm}$, glutaraldehyde, formalin, heat treatment of $65 \square \mathrm{C}$ or above, and acidic $(\mathrm{pH}<3)$ may be effective for inactivating SARS-CoV-2. The SARS-CoV-2 can remain infectious on the inanimate surfaces for up to 9 days so laboratory personnel should be aware of the need for following the biosafety protocols while processing the specimens.

Keywords: Coronavirus, SARS-CoV-2, microbiology, biosafety, disinfection

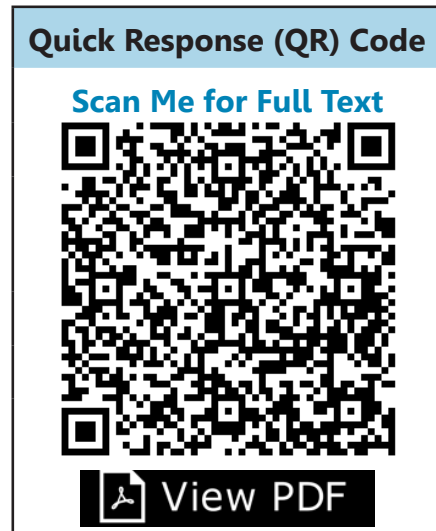

\section{Article Info}

Received: 12 July 2020;

Accepted: 2 October 2020;

Published Online: 3 October 2020

\section{How to cite this article in Vancouver Style?}

Roman M, Sidra saleem, Shah Jahan, Husnul Hayat, Faiz ul Haq, Abdul Waheed, Muhammad Nadeem. Preventive Guidelines for Disinfection and Microbiological Processes During Handling of COVID-19 Samples. Europasian J Med Sci. 2020; 2(2): 59-63. https://doi.org/10.46405/ejms.v2i2.179

\section{Disclaimer}

Conflict of Interest: None Declared;

Source of Support: Nil

Copyright: ( $) 2020$ by author(s). This is an open access article distributed under the terms of the Creative Commons Attribution International License 4.0 (http://creativecommons.org/licenses/ by/4.0/) which permits unrestricted use, distribution, and reproduction in any medium, provided the original work is properly cited.

\section{Publisher's Note}

The Europasian Journal of Medical Sciences (EJMS) (www.europasianjournals.org) is an official Journal of Nirvana Psychosocial Care Center \& Ressearch Institute (www.nirvanapscc.com). The Journal as well as publisher remain neutral with regards to any jurisdictional claims in any published articles, its contents and the institutional affiliations of the authors. 


\section{INTRODUCTION}

Since December 31, 2019, an outbreak of an atypical respiratory disease, similar to pneumonia, has been identified in Wuhan city, China. The infection is caused by a novel coronavirus (2019-nCoV) recognized as severe acute respiratory syndrome coronavirus-2 (SARS-CoV-2). After exposure to the SARS-CoV-2, the infected patients present symptoms such as cough, fever, and shortness of breath. ${ }^{1}$ As of June 09, 2020, 7039918 laboratoryconfirmed cases of the corona virus disease-2019 (COVID-19), with the mortality rate of 6\% (404396 deaths), have been reported worldwide. However, the mortality rate has varied among the countries. ${ }^{2}$ The aim of this context is to provide clear and brief laboratory biosafety related recommendations using disinfectants and inactivation methods commonly used in microbiology laboratories which could be potentially effective on SARS-CoV-2. It is necessary for the laboratory personnel to handle clinical specimens safely for the diagnosis of COVID-19.

\section{Risk and precaution for the microbiology laboratory personnel}

Aerosol droplets are considered to be the primary route of COVID-19 transmission. However, airborne transmission may also be possible. Most of the healthcare personnel are exposed during the aerosol-generating procedure (such as extubation, and endotracheal intubation), which puts them in a high risk of exposure, and therefore, infection. ${ }^{3}$ The samples from the suspected patients are submitted to the microbiology laboratories for the diagnosis of COVID-19. Therefore, it is necessary for the healthcare personnel to take adequate precautions for their own protection. All the specimens collected for laboratory screening should be considered as potentially infectious as recommended by the World Health Organization. ${ }^{4}$ Healthcare workers involved in collecting, handling, processing, and transportation of clinical samples should follow the biosafety practices and standard precautionary measures (see Table 1) to reduce the possibility of the exposure to the pathogen. Recently, interim laboratory biosafety guidelines for handling and processing the samples associated with COVID-19 have been released by the Centers for Disease Control and Prevention (CDC), and are summarized in table $2 .^{5}$

Unfortunately, there is limited scientific data about the suitable disinfectants for the inactivation of SARS-CoV-2. There are recommended disinfectants for the inactivation of similar coronaviruses, e.g., those responsible for the Middle East respiratory syndrome (MERS) and severe acute respiratory syndrome (SARS), which are likely to be effective for the inactivation of SARS-CoV-2. ${ }^{6}$

The highest concentration of SARS-CoV-2 has been observed in the respiratory specimens compared to the non-respiratory specimens as the virus is present in lower concentration in urine, blood, and stool. Of note, laboratory safety practices recommended for managing the non-respiratory viral specimens (e.g., Ebola virus) are clearly distinct from those recommended for the SARS-CoV-2 specimens. Airborne transmission is a significant mode of SARS-CoV-2 transmission. However, there is no information about the definition of infectious dose (ID) for this virus. ${ }^{7}$

In light of earlier information on the SARS-CoV-2,

\section{Table 1: SARS-CoV-2-related standard precautions by the World Health Organization ${ }^{4}$}

1. Ensure that the laboratory personnel who collect the specimens should follow good microbiological practices \& procedures and use suitable personal protective equipment (PPE), such as a medical mask, a long-sleeved gown, eye protection, and gloves. If there is a risk of aerosol generating from the specimen, healthcare worker should wear an N95 mask, or the equivalent.

2. Ensure that all the healthcare workers abide safe handling practices and spillage decontamination procedures while transporting the specimens.

3. During transportation, keep the specimens in a leak-proof container, such as (i) plastic biohazard specimen bag, with the label containing the patient's information on the primary specimen container, (ii) secondary container containing a distinct sealable pocket for the specimen.

4. The laboratories in the healthcare facilities should utilize Biosafety level-2 (BSL-2) or BSL-3 facilities with appropriate biosafety for handling the SARS-CoV-2.

5. Avoid the use of pneumatic tube systems for transporting the specimens. All the specimens should be hand-delivered whenever possible.

6. On the laboratory request form, clearly mention each patient's full name, date of birth, and suspected SARS-COV-2 of potential concern. 
the handling and processing of the respiratory specimens from suspected patients takes place in the microbiology laboratory, thereby posing the highest risk to the laboratory personnel. Other section of the laboratory, such as chemistry, blood bank, and hematology, where non-respiratory specimens such as urine and blood products are processed, are exposed to a rather lower titer of the virus. Specimen suspected to be positive for SARS-CoV-2 should be handled in biosafety level-2 (BSL-2) or equivalent facility for the molecular testing. However, BSL-3 facilities are required with enhanced practices for the virus culture (Table 1). ${ }^{4}$

\section{Persistence of coronaviruses on the inanimate surfaces}

Human to human transmission of SARS-CoV-2 has been documented, with droplets being a major source of virus spread. Approximately $10^{8}$ viral particles are found in $1 \mathrm{~mL}$ of sputum. ${ }^{8}$ However, the persistence of coronaviruses on the inanimate surfaces too has been described, which can enable virus transmission from the contaminated surfaces during specimen processing. Previous studies have revealed that the coronaviruses such as the Middle East respiratory syndrome (MERS) coronavirus, endemic human coronavirus ( $\mathrm{HCOV}$ ), and severe acute respiratory syndrome coronavirus, can remain infectious for up to 9 days on inanimate surfaces such as glass, metal, or plastic. ${ }^{9}$

\section{Microbiological processes and Inactivation of coronavirus by the disinfectants}

A variety of disinfectants can be used to disinfect the inanimate surfaces. ${ }^{7}$ Exposure of surface disinfectants such as ethanol (62-71\%), sodium hypochlorite $(0.1 \%)$, or hydrogen peroxide $(0.5 \%)$ for $1 \mathrm{~min}$ can be efficiently used for significant reduction and inactivation of virus. In contrast, other biocidal agents such as $0.02 \%$ chlorhexidine digluconate and $0.04 \%$ benzalkonium chloride were less effective ${ }^{9}$. Irradiation with ultraviolet light for 60 min showed undetectable levels of viral infectivity in the culture medium. ${ }^{10}$ Ethanol $(78 \%$ $95 \%)$, 2-propanol (70\%-100\%), the combination of 2-propanol (45\%) with 1-propanol (30\%), formaldehyde $(0.7-01 \%)$, povidone iodine $(0.23$ $7.5 \%)$, and glutaraldehyde (0.5-2.5\%) significantly reduced the infectivity of coronavirus by $\log _{10}$ Sodium hypochlorite was effective at $0.21 \%$ concentration. Benzalkonium chloride, at $0.2 \%$ concentration, had no efficacy against coronavirus, in contrast to $0.05 \%$, which was more effective. ${ }^{9}$

Microbiology laboratories are often involved in the routine microbiological processes (detergentdisinfectants) that can result in the inactivation of many viruses, such as influenza virus and coronavirus. $^{11}$ SARS-CoV is inactivated by glutaraldehyde and formalin in the temperatureand time-dependent manner. While the effects of these disinfectants were inhibited at $4{ }^{\circ} \mathrm{C}$, formalin significantly reduced the infectivity of the SARS-CoV on day 1 at room temperature, and glutaraldehyde inactivated the virus after 1-2 days of incubation at $37{ }^{\circ} \mathrm{C} .{ }^{12} \mathrm{~A}$ previous study reported that the coronaviruses were inactivated when incubated at $56{ }^{\circ} \mathrm{C}$ for $90 \mathrm{~min}, 67^{\circ} \mathrm{C}$ for $60 \mathrm{~min}$, and $75^{\circ} \mathrm{C}$ for 30 min. ${ }^{10}$ Other methods used in the microbiology laboratories include heat treatment at $65^{\circ} \mathrm{C}$ for 20 minute, UV treatment ( $254 \mathrm{~nm})$, acid treatment $(\mathrm{pH}$ $<3)$, glutaraldehyde, and formalin treatment.

Before performing tests all laboratories should complete risk assessment for site specific and activity specific to find and mitigate risk.

All health should be educated about the usage and the risk come from the biological agents. Each lab

\section{Table 2. Summary of the CDC quidelines on the Interim Laboratory Biosafety ${ }^{5}$}

1. Healthcare worker should use appropriate personal protective equipment (PPE) such as N95 respirator, disposable gloves, facemask, eye protection, and laboratory coat, when dealing with the potentially infectious specimens.

2. Any process that might result in aerosol generation, such as vortexing, should be performed in the Biological Safety Cabinet class-II (BSC-II). Centrifugation should be done by using an appropriate physical containment device (e.g., sealed rotors with centrifuge safety buckets). Preferably, buckets and rotors should be loaded and unloaded in a BSC-II.

3. After processing the specimens, decontaminate the equipment and laboratory work surfaces with appropriate disinfectants as recommended for other respiratory pathogens, such as other human coronaviruses and seasonal influenza viruses.

4. For SARS-CoV-2-related laboratory waste, follow appropriate procedures associated with other respiratory pathogens, such as other human coronaviruses and seasonal influenza viruses.

5. Preparation and fixation (by chemical or heating) of the smears for microscopic analysis should be done in a certified BSC-II. 
should analyze a risk assessment before performing the intended tests. Appropriate personal protective equipment should be firm after a detailed risk assessment and should be used by health personnel. Personal protective equipment should include of gloves, gown, eye protection, mask and shield that will be selected in accordance with the risk posed by the type of pathogen and procedure. When health care worker is handling a blood sampling for serological tests, they should follow Good Microbiological Practices and Procedures. ${ }^{13}$

All environmental surfaces including standard floor, objects and walls in SARS-CoV-2 isolation areas should be disinfected with solutions of $1000 \mathrm{mg} / \mathrm{L}$ chlorine. Disinfection should be done three times daily and should be repeated each time when there is contamination. ${ }^{14}$

Thermal inactivation is also an effective method for inactivation of SARS-CoV at $56^{\circ} \mathrm{C}$ to $60^{\circ} \mathrm{C}$, however in the protein presence (20\%) $2 \log _{10}$ reduction occur at $56{ }^{\circ} \mathrm{C}$ after 30 minutes. In the presence of protein the SARS-CoV inactivation should be done with heat treatment of $60{ }^{\circ} \mathrm{C}$ for at least 30 minute. For fixation procedure in the hospital and laboratory the common method of inactivation is using chemical. ${ }^{15}$

\section{CONCLUSION}

In conclusion, SARS-CoV-2 can remain infectious on the inanimate surfaces for up to 9 days. Laboratory personnel should be aware of the need for following biosafety protocols while processing the specimens. Surface disinfection with sodium hypochlorite $(0.1 \%)$, ethanol (62\%-71\%), or hydrogen peroxide $(0.5 \%)$ can be efficient against the SARS-CoV-2 with an exposure time of $1 \mathrm{~min}$. However, UV light, glutaraldehyde, formalin, high temperature, and extreme $\mathrm{pH}$ effectively inactivated the SARS-CoV-2.

Authors' contributions: All the authors have contributed equally towards the preparation of the manuscript.

\section{REFERENCES}

1. 1.McMichael TM. COVID-19 in a long-term care facility-King County, Washington, February 27March 9, 2020. MMWR. Morbidity and Mortality Weekly Report 2020, 69. http://dx.doi.org/10.15585/ mmwr.mm6912e1 [Google Scholar] [PubMed]

2. World Health Organization,Coronavirus disease 2019 (COVID-19): situation report,72.2020. https:// doi.org/10.1186/s40779-020-00240-0 [Google

\section{Scholar] [BMC]}

3. Ng K, Poon, BH, Kiat Puar $\mathrm{TH}$, Shan Quah JL, Loh WJ, Wong YJ, Tan TY, Raghuram J. COVID-19 and the risk to health care workers: a case report. Annals of internal medicine 2020. https://doi.org/10.7326/ L20-0175 [Goog scholar] [AMC]

4. World Health Organization. Infection prevention and control during health care when novel coronavirus ( $" \mathrm{nCoV})$ ) infection is suspected: interim guidance, 25 January 2020. 2020.WHO/2019-nCoV/ SurveillanceGuidance/2020.6[Google scholar] [WHO]

5. Sick PG. Interim Laboratory Biosafety Guidelines for Handling and Processing Specimens Associated with Coronavirus Disease 2019 (COVID-19). 2020. https://www.cdc.gov/coronavirus/2019-ncov/index. html [Google scholar] [CDC]

6. Henwood AF. Coronavirus disinfection in histopathology. Journal of Histotechnology 2020, 43 (2), 102-104. https://doi.org/10.1080/01478885. 2020.1734718 [Google Scholar]

7. Iwen PC, Stiles KL, Pentella MA. Safety considerations in the laboratory testing of specimens suspected or known to contain the severe acute respiratory syndrome coronavirus 2 (SARS-CoV-2). American Journal of Clinical Pathology 2020, 153 (5), 567570. https://doi.org/10.1093/ajcp/aqaa047 [Google Scholar] [AJCP]

8. Kampf G. Potential role of inanimate surfaces for the spread of coronaviruses and their inactivation with disinfectant agents.Infection Prevention in Practice.2020,2(2),100044. https://doi.org/10.1016/j. infpip.2020.100044 [Google Scholar] [sciencedirect]

9. Kampf G,Todt D, Pfaender S, Steinmann E. Persistence of coronaviruses on inanimate surfaces and their inactivation with biocidal agents.Journal of Hospital Infection 2020,104(3),246-251. https:// doi.org/10.1016/j.jhin.2020.01.022 [Google Scholar] [sciencedirect]

10. Dong JH. Stability of SARS coronavirus in human specimens and environment and its sensitivity to heating and UV irradiation. 2003. BES, 01 Sep 2003, 16(3):246-255 [Google Scholar] [PMC]

11. Weinstein RA, Hota B. Contamination, disinfection, and cross-colonization: are hospital surfaces reservoirs for nosocomial infection? Clinical infectious diseases 2004, 39 (8), 1182-1189. https:// doi.org/10.1086/424667 [Google Scholar] [IDSA]

12. Darnell ME, Subbarao K, Feinstone SM, Taylor DR. Inactivation of the coronavirus that induces severe acute respiratory syndrome, SARS-CoV. Journal of virological methods 2004, 121 (1), 85-91. https:// doi.org/10.1016/j.jviromet.2004.06.006 [Google scholar] [Sciencedirect]

13. Ağalar C, Engin DÖ. Protective measures for 
COVID-19 for healthcare providers and laboratory personnel. Turkish journal of medical sciences. 2020 Apr 21; 50(SI-1):578-84.doi: 10.3906/sag-2004-132 [PMC] [PubMed] [Google Scholar]

14. Centers for Disease Control and Prevention, 2020. Interim US guidance for risk assessment and public health management of healthcare personnel with potential exposure in a healthcare setting to patients with coronavirus disease (COVID-19). Centers for Disease Control and Prevention.https://www.cdc. gov/coronavirus/2019-ncov/hcp/guidance-riskassesment-hcp.html

15. Rabenau HF, Cinatl J, Morgenstern B, Bauer G, Preiser W, Doerr HW. Stability and inactivation of SARS coronavirus. Medical microbiology and immunology. 2005 Jan 1;194 (1-2):1-6. DOI 10.1007/ s00430-004-0219-0 